\title{
Teaching
Anthropology
}

2021, Vol. 10, No. 2, pp. 83-92.

\section{When Students Do Not Aspire to Become Professional Anthropologists}

\author{
Leonidas Sotiropoulos \\ University of Patras
}

\begin{abstract}
Studies in anthropology have been influential in Greece in the recent decades. Anthropological concepts and analysis have prompted a critical assessment of Greek culture and brought this academic discipline close to history and folklore studies. Furthermore, today in Greek universities one finds several courses that teach this subject, plus some whose approaches are influenced by ethnography and the anthropological perspective. Given that only a small percentage of the students learning anthropology in Greek universities will eventually become professional anthropologists, my teaching experience leads me to the position that their acquaintance with anthropology should include a correlation of knowledge received during their studies to aspects of their daily life. Consequently, this article examines how teaching may encourage a fragmentary use of ethnography and a strong reflexive attitude from the students' side, leading the latter to the exploration and evaluation, in a heuristic way, of their personal worldview and ethos.
\end{abstract}

Keywords: Ethnography, folklore, reflexivity, vocation, worldview

\section{Introduction}

It can be argued that knowledge and ideas deriving from anthropological studies have had an impressive influence well beyond the strict boundaries of this discipline, thus indicating that the aims in teaching anthropology may not be limited to would-be anthropologists. Seymour Papert, one of the pioneers in advocating computational thinking, while arguing for the advantages of introducing computers in the classroom (1993), employed the term bricolage, making due reference to Lévi-Strauss. He also mentions the "ethnographic" work of Jean Lave (1988) that through reference to "kitchen maths" - the arithmetic involved in calculating during cooking the quantities prescribed by a recipe - stresses the distance separating knowledge acquired in school from its use in everyday activities. The diffused anthropological knowledge Papert has learned was thus put by him to novel use. Likewise, Weiss (1986) has pointed to the manner in which Kandinsky's paintings were influenced by the ethnographic work he conducted among the Zyrians during his university years. Kandinsky's art and ethnography was further conflated by portraying him as a shaman and artist (Weiss, 1995).

If the teaching of anthropology is momentarily dissociated from the processes necessary to ensure the continuity of this specific academic discipline, the varied and far-reaching effects derived from such a learning may conceivably appear in the foreground. Still, if the distinguished figures of Kandinsky and Papert were able to preserve the strange fruits that resulted from their acquaintance with anthropology, in less eminent instances the traces of such results may be faint or are perhaps lost, as they may not find their way in the printed word of academic discourse, or may be submerged - though perhaps significant to the individual - by the ephemeral quality of social life. Difficulties are thus created in any attempt to discuss the profits deriving from studying anthropology in cases where students may not further their learning and become professionals in this field, or their career does not turn out to be illustrious. However, since teaching anthropology in Greece is a case in point, the present article attempts an investigation of one way teaching can respond and open up to these subtle outcomes, while being accommodated within facets of the educational circumstances in this country.

Obviously, the position expressed relates more to me and my teaching experience, and also reflects aspects of what has drawn me to anthropology. Thus, though the article commences with reviewing in broad terms the Greek scene in regard to teaching anthropology, indicating the large numbers of students that are acquainted with this subject in a country where respective vocational opportunities are limited, I shall eventually focus on my teaching anthropology to prospective educators; a few comments will also be added, deriving from my 
teaching for several years, a course on Modern Greek culture at the Hellenic Open University. My personal involvement with anthropology started decades back with a somewhat standard dissertation at the time on the institutions and everyday life of a Greek village. Opting later to teach mainly in a university Education Department, I adjusted my teaching accordingly, and it is on this experience that what follows is primarily based.

\section{Historical outline of teaching anthropology in Greece}

A symposium held in September 1986 on the island of Mytilene, with the title "On the Horizons of Current Anthropological Research in Greece and the Establishment of a Department of Social Anthropology at the University of the Aegean", inaugurated the opening of the said Department, which was the first in Greece to offer degrees in social anthropology. It can be argued that teaching anthropology in this country symbolically commenced at that point. The symposium program mentions 37 scholars who presented papers during the sessions, a number indicating that teaching anthropology was preceded by an intense period of fieldwork in the area. Three generations of anthropologists who had done research in Greece already existed at the time, the first having done fieldwork in the 1950s and 60s, the second in the 70s and early 80s, while these belonging to the third were just completing their research projects. John Campbell (1964), for example, had studied the Sarakatsani during 1954-55; some of his students (Just, Hirschon, Herzfeld) had completed their fieldwork by the late 70s, while Jane Cowan presented in the symposium her recent work that was conducted under the supervision of Herzfeld. A long way had been crossed since the Greek-Cypriot John Peristiany was awarded in 1938 the second D.Phil. in Anthropology by the University of Oxford for his work on the Kipsigis (Rivière, 2007, p. 52); Peristiany, who later turned his interest to the examination of Mediterranean values (1966), was the Vice-Chairman of the Organizing Committee of the said symposium, and one of the various publications that issued from it (Papataxiarchis \& Paradellis, 1992) was dedicated to him. Consequently, when the teaching of anthropology started in the University of the Aegean, and a few years later energetically at Panteion University, a significant corpus of studies about aspects of Greek society and culture existed so as to permit that such teaching could have Greek themes as one of its foci, though it should be noted that this focus related more to research interests and also extended and included scientific interests linked to a wider area that encompassed the neighbouring countries to Greece.

Secondary tributaries to the primary trends mentioned above also existed. For example, a course in cultural anthropology was being taught since 1986 in the Department of Early Childhood Education at the University of Patras; Alke Kyriakidou-Nestoros had been teaching a course of folklore with extensive anthropological commentaries at the University of Thessaloniki as far back as the late 1970s; similarly, classes taught since the late $80 \mathrm{~s}$ at the University of Ioannina were employing mixed perspectives of anthropology, folklore and history. Though anthropological teaching in Greece has retained its distinctness, it was also frequently in close proximity with that of folklore studies, a discipline already well-established in that country all through the 20th century. One of the latter's founding-fathers, Nikolaos Politis, had been teaching it in the University of Athens for roughly three decades, since 1890; his pupils, Megas and Kyriakidis taught Laografia (Folklore) respectively at the Universities of Athens and Thessaloniki. Today, the Greek Folklore Society, an association founded by Politis in 1908/9, mentions at its internet site the scholars that are presently teaching folklore in Greek universities; of these, half can also claim an anthropological identity. The Department of History, Archaeology and Folklore at the University of Thessaly was renamed in 2002 as Department of History, Archaeology and Social Anthropology, indicating a proximity of anthropology to - but also a differentiation from - both folklore studies and history.

In the more than thirty years that have elapsed since the 1980s, not only have several university departments of social anthropology or anthropology plus folklore/history studies evolved in Greece, but also additionally multiple courses in anthropology have found a place in university programs that do not lead to the acquisition of an anthropology degree (indicatively: courses in the Department of Theatre Studies at the University of the Peloponnese, in the Department of Fine Arts and Sciences of Art at the University of Ioannina, in the Department of Traditional Music at the Technological Educational Institute of Epirus). Such teaching has produced a significant number of highly qualified, commendable research works. Yet the students attending such courses were by far more numerous than the limited few who continued with an anthropological career and became distinguished scholars of this discipline.

Undergraduate studies in Greece (and also several post-graduate programs) do not charge tuition fees, and the number of students admitted to universities is to a great extent fixed by the State, the latter insisting on large numbers of freshmen admissions. These factors facilitate the existing desire of Greek families to equip their 
children with a university degree (a tendency that has been reinforced rather than weakened in the roughly ten years of economic crisis and youth unemployment that Greece has been lately facing). Despite the limited vocational scope of an anthropology degree, the number of students who opt for such studies remains high; several hundred are awarded a B.A. degree in anthropology every year, and the estimate that more than a thousand attend annually anthropology courses may not be farfetched. Consequently, one may conclude that teaching anthropology (at a university level) to students who will not become anthropologists is largely the case in Greece today, where a large number of anthropology degrees are annually awarded and several courses in anthropology exist in degree programmes with a different academic orientation. The few university posts that opened up during the last decade in Greece - due to the country's economic predicament - hinder entrance in to academia. Though graduates in anthropology may find work as social scientists in the public or private sector, such opportunities do not abound. In a sense this is a more general phenomenon characterizing Greek tertiary education, indeed one that progressively intensifies. Even in my Education Department, where the vocational orientation is prominent, graduates in the past decades were faced with the probability of a period of unemployment before their eventual employment as teachers. Without thus presently intending to delve into the private wishes or feelings of university students in Greece who come in contact with anthropology, we may assume their awareness that, given the prevailing conditions in this county, in pursing such studies their future chances of working purely as anthropologists are slim. Hence, though anthropology courses provide the students that attend them with several important competences and abilities, there is a quandary as to how an anthropology teacher can best train students, so that the knowledge they acquire about this discipline could be of the utmost value to them.

\section{Convergences and divergences}

Some preoccupations of mine, regarding the students of anthropology and their possible outlook and response to this subject plus their eventual profit from studying it, prompt a brief elaboration on facets of the abovementioned. These concerns, though pertaining also to my principal teaching of anthropology at an Education Department, are perhaps more evident in my teaching, for a decade, a course on Modern Greek Culture from an anthropological perspective at the Hellenic Open University. This was a semi-structured course, part of a program leading to a B.A. in "Greek Civilization", obviously a program providing general knowledge with hardly any vocational orientation. The guidelines for this course proposed an assortment of folklore and anthropology viewpoints, so a short reference to this broader scene may be appropriate.

The gradual introduction of anthropology in Greece from the 1970s onwards, initially through acquaintance with the writings of foreign anthropologists, influenced folklore studies in that country, and was also possibly affected by them, to the extent that anthropology like folklore studies focused mainly on the study of the local. Folklore studies adopted selectively research tools or elements belonging to the anthropological theoretical framework, and a wish of folklorists developed, as Nitsiakos (2008, pp. 48-53; 2018) claims, for an epistemological dialogue between the two disciplines, though he adds that anthropologists did not until recently respond to such an offer. Those teaching anthropology and/or folklore in Greece today have a different theoretical orientation from past generations of mostly German-trained folklorists. To the extent that the latter were concerned with tradition and with proving the historical continuity of the nation, the aim of their teaching was, it has been argued, to formulate a Greek identity. The way folklore studies influenced, in its initial stages, education in Greece is perhaps a complicated issue that remains beyond the scope of the present article. Though specific instances of how folklore intervened on a local level have been examined (e.g. Manos, 2018), we may limit ourselves to the general remark expressed by Herzfeld (1986, pp. 8-10), who in his anthropological study of early folklorists, comments that it is not easy to verify and understand how feedback could operate, whereby the results of folklore studies returned to the people from which data was initially extracted. This delicate indefiniteness of feedback, however, raises preoccupations for an anthropology teacher, and possibly merits being briefly put in a historical and social context. The significance of such an eventual interplay in the social environment that envelopes the student of an anthropology class may thus not be bypassed.

The appearance of an interest in folklore in Greece coincided to some extent with the establishment of the Greek State after the War of Independence (1821-1829). Initial attempts to document aspects of the indigenous culture centred on the customs and oral literature of this county's rural areas. By the end of the 19th century studies became more systematic and rigorous, though often guided and restricted by the European paradigms that influenced them. Yet, such studies have also motivated 'amateurs' to attempt to collect and/or 'rescue' fragments of what they thought was representative of their culture. Politis encouraged school teachers posted in the countryside to acquire data, based on questionnaires that he provided. Local dilettanti, historiographers, and 
artists were also interested in folk cultural expressions and considered their recordings of such events as contributing to the scholarly viewing of their culture. "Local patriotism has been the constant motivation to the local intelligentsia for the collection of their lore although they had little tutoring in the subject" (Peristiany, 1968, p. 268). To the above one may add that often folklore has recently been turned into folklorismus by those it describes (Puchner, 2011).

Though folklorists have long since stopped studying only rural areas and tradition, their present subject-matter plus the eventual diachronic, lingering influence of past folklore studies and the issues it raised are still close, one may suspect, to the quotidian life of the potential student who attends an anthropology class. If in Greece indigenous interest in folklore studies proliferates, anthropological work, though often keeping a distance from the people it studies, may also be accessible to them. For example, anthropologist Panayotis Panopoulos (2003), who studied the symbolic significance of animal bells on Naxos, is contemplating the creation of a soundscape on this island, thus sensitizing the islanders to this aspect of their culture; his interest in the anthropology of sound has been expressed in audiences that included the deaf and hard of hearing.

Greece was not unique in that the Arts were also involved in attempts to portray local culture, often creating a rich imagery that found its place in the minds or hearts of the people depicted. Indicatively, the Thirties Generation, a group of Greek writers, poets and intellectuals, were preoccupied with the concept of Greekness and their work reflects a tendency to treat what they regarded as Greek culture in an archetypal way: that is, to dip into it and come up with creative confluences, essaying to grasp its essence (Tziovas, 2011). Painters in different periods since the middle of the 19th century have adopted various styles and themes so as to depict the quintessential "Greek" qualities (Vaos, 2000). The importance of this for teaching anthropology in Greece, is that a teacher may be confronted with aspects of the above mentioned tendencies, which possibly exist in a medley in the students' minds or are ingrained in their experiencing of social conditions. To the extent that teaching anthropology may refer to aspects of Greek culture, such teaching - as my experience of teaching at the Hellenic Open University indicated - should be aware of the contingent renegotiation, retrospection, and preoccupation that Greeks themselves may have in regard to their self-image, their identity, their roots, and more generally their society.

Anthropology introduced a more critical consideration of what Greek culture consists of than that proposed by folklore studies up till the 1960s, in that it contributed its theoretical framework and vocabulary as a means of analysis, thus affecting the teaching of both these subjects as well. Anthropology, being comparative and ecumenical, may prompt Greek students attending lessons on anthropological subjects to reduce their ethnocentrism, while comprehension of this discipline's paradigms and ethnographies may be the result of a fusion of horizons (Gadamer, 2012). In acquainting students with the anthropological perspective, even when such teaching is about other cultures, about say the meaning attached to handkerchiefs (Hendry, 2008, pp. 16-18) or the significance of the 'gift', the knowledge acquired by the students will inevitably have to find its place through being incorporated in their worldview. Still, difficulties are not obliterated in attempting to define what exactly is being learned and for what reason, in cases like this of Greece, where part of the material taught may be very close to the everyday life of the people who receive such teaching. The obvious answer, that a new scientific perspective permits a new outlook of things entails, possibly on a different scale, most of the wellknown problems of doing fieldwork in one's own country. The marking of the threshold, which if crossed turns one into a 'native', or conversely transforms a 'native' into a researcher thus becomes a crucial issue to be reckoned with, particularly when the attending of anthropology classes does not transform attendees into fulltime anthropologists.

From my particular viewpoint, I perceive that teaching anthropology in Greece today is thus contingent on the above described convergences and divergences, to which we may possibly add one more facet. Anthropological research may possibly retain a degree of independence from the eventual impact its results may have on a general public. In teaching anthropology under the described circumstances, however, so as to avoid the eventuality of gliding towards imprinting on the student an ideology, a certain open-endedness in regard to the students' response may perhaps be appropriate. In this respect the heuristic potential of the knowledge gained by the student, coupled with the ethnographic method, may soften the dividing line between researcher/researched, and could thus prove empowering. The goals of my teaching anthropology at an Educational Department that reflect also on my teaching at the Hellenic Open University should be viewed along these lines. 


\section{Considering the goals of teaching anthropology}

In teaching there is always an element of the 'potential', pertaining to the uncertainty as to the outcome that accompanies any attempt to communicate something to another and persuade him/her to accept it as useful knowledge. Teachers may try to influence one's worldview or ethos in various ways, but even if they succeed, the possible results of such a teaching may be undetermined or may appear deep into the future and hence be traceable with difficulty. The kitchen maths that Papert mentions, or the ethnographic influences traced in Kandinsky's artwork, testify that the way learned anthropological knowledge can be used may be somewhat undefined. Furthermore, anthropological ideas may spread and influence a people's perspective, though the origin that created such shifts in outlook may often be disremembered.

Needham $(1978$, p. 25) has proposed that reading an anthropological monograph may be as equally enriching as reading a literature classic. In accepting such an attitude, the resulting responses to anthropological learning may be as varied as the eventual influence on a person of the reading of a Shakespeare play. In the classes of anthropology that I teach, I accept this open-endedness in regard to learning anthropology, yet I also consider that students can profit when equipped with an elementary ability to use anthropological tools, as I also deem that any anthropological knowledge that they acquire would benefit from a close association with the student's inner self. When students learning anthropology do not intend solely to contribute to the latter's propagation, as indeed is the case in Greece, the teaching of this subject may open up, encouraging students to construct, in a bricoleur fashion, their own understandings from the 'input' the teacher presents them with. Or, to the extent that students may pursue an interest originating from their inner self, they may chart, from an acquaintance with anthropology, their personal heuristic trajectories, like Kandinsky (Sotiropoulos, 2017). The 'input' presented by the teacher is important, but does not accordingly result 'in a black box manner' in the production of the expected 'output' (Berthoud-Papandropoulou \& Sotiropoulos, 2012; 2014). Yet, such an 'input' has for the teacher some meaning, some potential, it constitutes an offering (see also Ingold, 2018) to the student. With no intention to generalize, and so as to explain better the structure of what I am arguing for, I shall focus, in the rest of this article, on some aspects of my teaching 'input' which was addressed to audiences of future educators, but also to students that wanted to enhance their understanding and knowledge of Greek culture. Further on, I shall also essay to tentatively correlate such teaching to the influences deriving from the academic environment I previously referred to.

\section{Fragmentary Anthropology}

The role of ethnography in teaching anthropology has been discussed from various angles. McGranahan (2014) indicated that it can be taught outside the field and stressed its potential to generate empathy. Ingold (2018), in his recent treatment of anthropology and education, downplays the importance of ethnography; yet, in my reading, he repositions this research method within the general theoretical framework of this discipline, and does not object to one's rudimentary acquaintance with the tools that ethnography entails. Within a Greek context the ethnographic lens may be used to perceive aspects of the indigenous culture that folklore studies or history have maybe addressed from adjoining viewpoints, but this research method can also be used in a more limited sense: that is, to focus on specific instances that one wants to examine deeper.

Though extended fieldwork will probably never be attempted by someone who is not a professional, a fragmentary, piecemeal use of ethnography may be highly important to the non-professional who may want at some point in time to understand better some detail of the environment in which he/she lives. In my teaching, addressed to future educators, which spans four courses, I consistently attempt to train them along these lines. Some quickly become competent at conducting small scale ethnographic research projects, usually within their class environment, but most of them merely become competent in the use of the tools for data collection utilized during an ethnographic study. Since ethnography entails hearing accurately what another tells you, and seeing things without automatically projecting on them explanations deriving from one's own ideas and preoccupations, students can profit from the acquisition of such skills. From coping with the difficulties involved in attempting during an interview to record another's point of view, to the training so as not to miss a word in a conversation, to observing something without jumping to arbitrary conclusions regarding its meaning or intentions, these elementary constituents of any good fieldwork could, I believe, be valuable tools. Students may use them in their future profession, be that school-teaching or any other field of work, or in their everyday life, so as to understand better, if and when they may wish, aspects of their social environment. Teaching along these lines entails - to use the famous example of Geertz (1993, pp. 6-7) - seeing the contracting eyelid, rather than uncritically interpreting that facial movement as a conspiratorial wink or say a parody, the ethnographic aim being to understand its 
particular meaning in context. For that purpose, both practicum but also illustrative anthropological examples in class are used. From training the students' capacity to observe while they are commuting in a bus and comparing what they have observed to the description in the opening pages of Spradley's book on the same topic (1980, pp. 5-6) or to that of McGranahan (2014), to encouraging them in trying to trace while reading an anthropological article how the researcher collected his/her data so as to arrive at his/her conclusions, to wondering about the objectivity of the claim that the small silvered and stoppered bottle in Pitt Rivers Museum contains an imprisoned witch, competences can be acquired that any good ethnographer has mastered. Students may also be exposed to the dilemma, so clearly posed by Popper (1972, p. 46), when they are faced with the request, "observe around you and record", through which they understand that observation is always selective. They can then examine such a realization side by side with Evans-Pritchard's commentary that "you will find in a good anthropologist's notebooks a detailed description of even the most commonplace activities" (1951, p. 80).

This brings us to the recognition of patterns. As ethnography differs from experimental research methods, in that what is asked or observed is not fixed in advance, pattern recognition is also an element that can be separated from a complete intensive fieldwork and used so as to examine in a systematic way, aspects of one's every day or professional environment. Since the times when Radin commented that "no one quite knows how one goes about fieldwork" (Evans-Pritchard, 1976, p. 240) multiple books on ethnographic techniques have been written, as well as works that provide a critical assessment of this research method. With their aid, one of the aims of teaching anthropology could be to bring students (who do not intend to become professionals in this field) in contact with the current theoretical discussions relevant to this research method and familiarize them with the increased sensitivity entailed in any anthropological attempt to understand a condition of life, which can lead to a better understanding of the self and to conceptualizing what 'other' or 'otherness' means.

Though I have alluded briefly to the possible didactics associated with such an aim, my intention was illustrative rather than demonstrative. Obviously, in attempting to equip students of anthropology with some elementary ethnographic tools, which they may apply in a fragmentary way, we also permit them to use such tools in an open-ended way. Furthermore, the knowledge acquired from their anthropological learning can be used in connection with other approaches, with say action research, case study analysis, Mezirow's transformative learning (Karalis et al., 2007). This could lead to a dilution of anthropology into the more general and fluid field of qualitative research. But since ethnography has been part of the historical trunk from which other qualitative methods have branched (Vidich \& Stanford, 1994), it may be opportune for someone coming in contact with anthropology in such a diluted state, to be aware of the initial theoretical premises from which his/her fragmentary use evolved. To explain that point further, one may refer to the fact that observation is proposed by Greek pedagogical manuals (Kakana \& Botsoglou 2016; Androutsou et al., 2016) as a means to better comprehending the students in the classroom; a systematic knowledge of the anthropological theoretical framework within which participant observation developed could enhance the systematic application of the above-mentioned pedagogical admonition. Students may also be reminded that such uses may in time distance themselves from their anthropological origins to the extent that the latter are forgotten; the theories of Lave and Wenger on learning through gradual incorporation in communities of practice initiated with anthropological studies, yet today such approaches have developed their own research equipment - that may not even be qualitative (e.g. Wenger et al., 2002, pp. 174-177).

\section{The Self and Reflexivity}

In learning anthropology whether one is focusing on one's own culture, or some other, or gets acquainted with the theoretical framework of this academic discipline, the active involvement of the self is entailed. What is more, to the extent that any partial attempt to use the anthropological research method is unhooked from the problematics that preoccupy this academic discipline, and the choice of its use is decided by the needs of the individual, reflexivity acquires an additional quality beyond the one it already has within the anthropological framework. For students whose contact with anthropology is impermanent, dependence on self-reflection is greater, since they lack the rigid epistemological discipline that a professional possesses in order to rein in their character tendencies while engaged in anthropological investigations. Increased self-reflection and selfquestioning in regard to the stereotypes, preoccupations, preconceptions, which govern one's viewing of the world and one's own culture may thus be necessary.

In a university environment where students address their own culture and worldviews through an anthropological lens, they may have to confront the resultant understanding with, as already mentioned, adjacent viewpoints deriving from say folklore, sociology, history, artistic representations, or even from the area of 
politics, or economics. In such a learning condition, which may even embrace the examining of aspects of one's own ethos, the emphasis on reflexivity may simply reflect a process of self-cultivation through "wrestling with problems without pre-defined answers, even without pre-defined formulations of the problems themselves" (Bohlin, 2008, p. 5).

Anthropology possesses a long tradition of reflexivity that is mainly directed in discerning the forces (social, historical, circumstantial) that influence the anthropologists' perception of the 'other'. To the extent however that in trying to understand a social issue self-knowledge could also be the desideratum, reflexivity may edge towards the sphere of psychology. Loosely speaking, any psychological aid that may enhance the researcher's reflexivity can be applied, provided it tunes in with the anthropological perspective in the general sense of favouring a 'grounded' approach to the individual. In this respect, facets of the Adlerian approaches align well with anthropology (Sotiropoulos, 2005). Other elements derived from psychology may also be of use, like say the roadblocks to listening of Gordon (2003), whereby one becomes aware that any criticism, avoidance, attempt to persuade, that lead to a non-acceptance of the issue under investigation, should be traced to some personal evaluation that may possibly produce bias, but may also be informative as to the researcher's personality trends.

Students in the courses that I taught were often fascinated by the reflexive element in an anthropological investigation but were also hesitant to be engulfed into the maze of self-searching that such an approach is proposing, thus limiting their profit from learning along this line. Still, to the extent that they may be perplexed by a situation that involves them, their anthropological training may not make it easy for them to disengage themselves from it through stereotyped thinking. A kindergarten teacher in a Greek mountainous area attributed to her anthropological sensitivity her tolerance when the program of her class was distupted by children who had to aid their families in agricultural work. She was however shocked when one day a five year old boy arrived late in class because he was detained so as to assist sheep to give birth - his hands being tiny could enter the sheep's vagina and pull the new-born out. She considered the specific act inhumane and had difficulty accepting the villagers' viewpoint in this instance; yet, she was also aware of the subjectivity of her viewpoint. She also comprehended that the intricacy of the situation she found herself in entailed that since she was not solely an outsider observing a situation but was also a teacher called to act upon it, she could not simply opt for the disengaged position of the researcher.

Though reflexivity may relate to a piecemeal application of ethnography, to the extent that one's research aim is motivated by some inner urge, reflexivity approximates introspection. If the choice of what to research evolves from the internal world of the individual, the latter becomes the centre of gravity of any attempt of anthropological understanding. In this respect, both in limited or wider endeavours to understand an issue or situation, such research attempts could merge well with heuristic research (Moustakas, 1990; 1994), a qualitative approach whose problematic is not decided by the academic discourse, but rather by the researcher according to his/her interests. The first stage in such research is to define precisely the research question that underlies one's vague personal desire to examine deeper a certain issue. A question pertinent to the individual should be clarified and become apparent. In incorporating elements from such a research method to an ethnographic investigation, the personal thoughts, reactions, experiences of the researcher are as much data to be analysed as any other information relating to the subject under research, and possibly the research can end when the answer reached is personally satisfactory (Sotiropoulos, 2017). Such an adapted heuristic research can be used in attempts to examine systematically a field of experience of the researcher, as this is moulded within a socio-cultural context. Thus, combining observations from an environment with an assessment of one's responses to it, one could aim at creating a holistic synthesis that is meaningful to one's self.

\section{Conclusion}

Summarizing, in teaching anthropology to students that shall not become anthropologists, reflexivity is, I believe, of high importance, given that the knowledge acquired (even if referring to the 'other') blends with their experiencing of their own culture. The assimilation by a person of what he/she has learned from anthropology is individualistic and involves his/her conceptualization of his/her social environment. If anthropology cuts everyday reality along a certain angle and studies the surfaces that are thus formed, non-anthropologists who have an ethnographic training may essay to utilize such an approach to the extent useful to them. However, since other ways of 'slicing' reality (be these from folklore, art, history, etc. or even deriving from a person's own experience) are available to them, a synthetic reflective process may at times be needed. As anthropology is not a 'solution providing' discipline, students could complement their anthropological knowledge with approaches like heuristic or action research, but even in such eventualities the basic element of self-reflection is present - and its 
presence, echoing perhaps the old well-worn abstract dictum that was inscribed in the navel of the ancient Greek

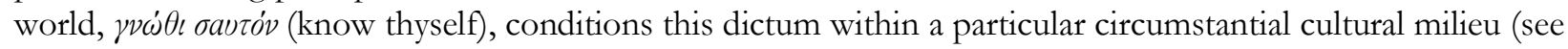
also Herzfeld, 1986, p. 144).

Closing on a personal note, I would comment that, while discussing an open-ended teaching as I have, it has occasionally been hard to distinguish whether one was referring to one's own experience, describing a teaching proposal or advocating a teaching method, and whether deep down, despite the announced open-endedness, a specific response from the students was not expected. Attempting to trace the results of one's teaching beyond the inadequate indications the scanning of exams results offer is not easy, particularly when students disengage from the discipline of anthropology after their studies. Though instances exist where students of mine confirm that they apply participant observation and self-reflection to their benefit, or solicit my aid in shaping a short research project, one may ask whether they are the rule or the exception. Inevitably thus the quandary that I mentioned in the beginning of this article, as to how students may profit to the outmost by attending classes in anthropology, remains part of the teacher's experience, in this case my teaching experience. When past students greet me in the street (Greece is a small country, and this does happen often), and kindly, with a general comment, refer favourably to my teaching they had attended, I wonder as to how they have incorporated it in their selves. In such meetings with half-forgotten faces, I may even secretly murmur to myself that on the anthropology I have taught, sediments can be found pertaining to provisional aspects of my ongoing personal trajectory towards a heuristic creative synthesis that would encompass my cultural surroundings plus their historical, folklore, literary or art representations, seen through my ethnographic sensitivity, as I experience these in my everyday life.

\section{Disclosure statement}

No potential conflict of interest was reported by the author.

\section{References}

Androutsou, A., Kortesi-Defermou, Ch. \& Tsafos, V. (2016). I Paratirisi os Ergaleio ton Ekpaideftikon (Observation as a Tool of the Educators). In S. Avgitidou, M. Tzekaki \& V. Tsafos (Eds.), Oi Ypopsifioi Ekpaideftikoi Paratiroun Paremvainoun kai Anastochazontai: Protaseis Ypostirixis tis Praktikis tous Askisis, (pp. 41-168). Gutenberg.

Berthoud-Papandropoulou, I. \& Sotiropoulos, L. (2012). Observation et action éducative. Skholê, 17, 153-160.

Berthoud-Papandropoulou, I. \& Sotiropoulos, L. (2014). L'univers des possibles dans l'apprentissage. Educational Journal of the University of Patras UNESCO Chair, 1(2), 25-33. https://doi.org/10.26220/une.2185

Bohlin, H. (2008). Bildung and Moral Self-Cultivation in Higher Education: What Does it Mean and How Can it be Achieved?. Forum of Public Policy, Retrieved 10 October 2018 from: https://files.eric.ed.gov/fulltext/EJ1099530.pdf.

Campbell, J. (1964). Honour, Family and Patronage: a Study of Institutions and Moral Values in a Greek Mountain Community. Clarendon Press.

Evans-Pritchard, E. (1951). Social Anthropology. Routledge \& Kegan Paul Ltd.

Evans-Pritchard, E. (1976). Witchcraft, Oracles, and Magic among the Azande. Clarendon Press.

Gadamer, H.-G. (2012). Truth and Method. Continuum.

Geertz, C. (1993). The Interpretation of Cultures. Fontana Press.

Gordon, T. (2003). Teacher Effectiveness Training: The Program Proven to Help Teachers Bring Out the Best in Students of All Ages. Three Rivers Press.

Hendry, J. (2008). An Introduction to Social Anthropology - Sharing our Worlds. Pelgrave MacMillan.

Herzfeld, M. (1986). Ours Once More: Folklore, Ideology, and the making of Modern Greece. Pella. 
Teaching Anthropology 2021, Vol. 10, No. 2, pp. 83-92.

Ingold, T. (2018). Anthropology and/as Education. Routledge.

Kakana, D.-M., \& Botsoglou, K. (2016). Theoritikes Paradoches tis Methodologias tis Paratirisis (Theoretical Premises of the Methodology of Observation). In S. Avgitidou, M. Tzekaki \& V. Tsafos (Eds.), Oi Ypopsifioi Ekpaideftikoi Paratiroun, Paremvainoun kai Anastochazontai: Protaseis Ypostirixis tis Praktikis tous Askisis, (pp. 16-40). Gutenberg.

Karalis, T., Sotiropoulos, L., \& Kampeza, M. (2007). La contribution de l'éducation tout au long de la vie et de l'anthropologie dans la préparation professionnelle des enseignants: réflexions théoriques. Skholê, hors série 1, 149- 155.

Lave, J. (1988). Cognition in Practice: Mind, Mathematics and Culture in Everyday Life. Cambridge University Press.

Manos, I. (2018). Opseis tis Ethnikis Sygkrotisis stin Ellada ton Archon tou 20ou Aiona mesa apo Keimena tou Periodikou "Laografia" (Aspects of the National Structuring in Greece during the Beginnings of the 20th Century derived from the Texts of the 'Folklore' Journal). In V. Nitsiakos \& P. Potiropoulos (Eds.), Laografia kai Anthropologia: mia Symvoli sto Dialogo, (pp. 127-166). I. Sideris.

McGranahan, C. (2014). What is Ethnography? Teaching Ethnographic Sensibilities without Fieldwork. Teaching Anthropology, 4, 23-36. https://doi.org/10.22582/ta.v4i1.421

Moustakas, C. (1990). Heuristic Research: Design, Methodology and Applications. Sage Publications.

Moustakas, C. (1994). Phenomenological Research Methods. Sage Publications.

Needham, R. (1978). Essential Perplexities. Clarendon Press.

Nitsiakos, V. (2008). Prosanatolismoi: mia Kritiki Eisagogi stin Laografia (Orientations: a Critical Introduction to Folklore). Ekdoseis Kritiki.

Nitsiakos, V. (2018). Eisagogi (Introduction). In V. Nitsiakos \& P. Potiropoulos (Eds.), Laografia kai Anthropologia, (pp. 13-27). I. Sideris.

Panopoulos, P. (2003). Animal Bells as Symbols: Sound and Hearing in a Greek Island Village. Journal Royal Anthropological Institute, 9, 640-656. https://doi.org/10.1111/j.1467-9655.2003.00167.x

Papataxiarchis, E. \& Paradellis, Th. (Eds.). (1992). Taftotites kai Fylo sti Sychroni Ellada: Anthropologikes Prosengiseis (Identities and Gender in Modern Greece: Anthropological Approahes). Kastaniotis.

Papert, S. (1993). The Children's Machine: Rethinking School in the Age of the Computers. Harvester Wheatsheaf.

Peristiany, J. (1966). Honour and Shame: the V alues of Mediterranean Society. Weidenfeld \& Nicolson.

Peristiany, J. (1968). Sociology in Greece.

Popper, K. (1972). Conjectures and Refutations: the growth of Scientific Knowledge. Routledge \& Kegan Paul.

Puchner, W. (2011). Dokimia Laografikis Theorias (Essays on Folklore Theory). Gutenberg.

Rivière, P. (2007). A History of Oxford Anthropology. Berghahn Books.

Sotiropoulos, L. (2005). Intégrer à la fois le "social" et l'"individuel" dans l'analyse ethnographique. Revue Européenne d'Ethnographie de l'Education, 4, 95-100.

Sotiropoulos, L. (2017). Incorporating Elements of Heuristic Research in Teaching Anthropology. Educational Journal of the University of Patras UNESCO Chair, 4(2), 33-38. https://doi.org/10.26220/une.2809

Spradley, J. (1980). Participant Observation. Holt, Rinehart and Winston, Inc. 
Teaching Anthropology 2021, Vol. 10, No. 2, pp. 83-92.

Tziovas, D. (2011). O Mythos tis Genias tou Trianta: Neoterikotita, Ellinikotita kai Politismiki Ideologia (The Myth of the Thirties Generation: Modernity, Greekness and Cultural Ideology). Ekdoseis Polis.

Vaos, A. (2000). Eikastiki Agogi stin Elliniki Ekpaideysi (Art Education in the Greek Educational System). Ellinika Grammata.

Vidich, A. \& Stanford, L. (1994). Qualitative Methods: their History in Sociology and Anthropology. In N. Denzin \& Y. Lincoln (Eds.), Handbook of Qualitative Research, (pp. 23-59). Sage Publications,.

Weiss, P. (1986). Kandinsky and Old Russia: An Ethnographic Exploration. Syracuse Scholar, 7(1), 43-62.

Weiss, P. (1995). Kandinsky and Old Russia: The Artist as Ethnographer and Shaman. Yale University Press.

Wenger, E., McDermott, R., \& Snyder, W. (2002). Cultivating Communties of Practice. Harvard Business School Press. 